\title{
Impact of HIV-Infection on Serum Liver Enzymes: A Comparative Study among Anti-retroviral Therapy (ART) Naïve Patients, ART Follow-Up Patients, and HIV Sero-negative Controls
}

\author{
Agbecha A." \\ Department of Chemical Pathology, Federal Medical Centre, Makurdi, Nigeria \\ Ikyernum J. A. \\ Department of Medical Microbiology, Virology Unit, Federal Medical Centre, Makurdi, Nigeria
}

\begin{abstract}
Background of study: There is emerging evidence that human immunodeficiency virus (HIV) infection, even in the absence of anti-retroviral therapy (ART) toxicity and other cofactors, may have a direct impact on liver pathogenesis. Aim: Based on this premise, our study determined the impact of HIV infection on liver enzymes as markers of hepatic function. Methods: the case-control study comprised of a total of 60 participants (30 males and 30 females) aged 18-60 years. The study compared aspartate aminotransferase (AST), alanine aminotransferase (ALT), alkaline phosphatase (ALP), cluster of differentiation (CD4+) cells among ART-naïve HIV patients ( $\mathrm{n}=20)$, followup HIV patients who were on highly active ART $(n=20)$ and apparently healthy controls $(n=20)$. Results: a significant $(\mathrm{P}<0.05)$ change was observed in the liver enzymes and $\mathrm{CD} 4+$ cells among the study groups compared. Specific changes showed that serum AST, ALP levels of ART-naïve patients were significantly $(\mathrm{P}<0.05)$ higher than that of follow-up and controls. Serum ALT levels of controls were significantly $(\mathrm{P}<0.01)$ lower than that of ARTnaïve and follow-up patients. The CD4+ cell count of ART-naïve patients was significantly $(\mathrm{P}=0.000)$ lower than that of follow-up and control groups. Conclusion: Liver enzyme abnormalities were observed in ART naïve HIV infected patients. Consequently, there is a need to monitor liver enzyme levels before and after initiation of therapy. Keywords: Human immunodeficiency virus; Aspartate aminotransferase; Alanine aminotransferase; Alkaline phosphatase; Cluster of differentiation $4+$ cells.
\end{abstract}

(9) (1) CC BY: Creative Commons Attribution License 4.0

\section{Introduction}

Human immunodeficiency virus (HIV) infection causes morbidity and mortality worldwide [1]. This infection causes systemic disease with many unrecognized complications other than acquired immunodeficiency syndrome (AIDS) [2].

Liver disease, often reflected by biochemical abnormalities of liver function is the most common non-AIDS related cause of death among HIV infected patients [3]. Approximately half of deaths among hospitalized HIV infected patients in the anti-retroviral therapy (ART) era have been linked to liver disease [4]. Liver disease ranges from asymptomatic mild elevations of liver enzymes to cirrhosis and end-stage liver disease with all its complications; ascites, esophageal varices, and hepatic encephalopathy. Liver cirrhosis is a more serious consequence with an estimated overall prevalence of $8.3 \%$ in HIV infected persons [5]. Previous studies have established that elevated serum activity of the two commonly used liver enzymes; alanine aminotransferase (ALT) and aspartate aminotransferase (AST), involved in the breakdown of amino acids reflects liver cell injury [6]. Opportunistic infections, AIDS-related neoplasms, concomitant infection with chronic hepatitis C virus (HCV), chronic hepatitis B virus (HBV), medication-related hepatotoxicity, alcohol abuse, and non-alcoholic fatty liver disease are some of the factors accounting for liver enzyme abnormalities in people infected with HIV [7-10].

Studies from developed countries have reported correlations between HIV viral load and aminotransferase serum levels in HIV-infected ART-naive patients [11]. There is emerging evidence that HIV infection, even in the absence of ART toxicity and other cofactors, may have a direct impact on the liver pathogeneses, non-alcoholic fatty liver disease, and non-alcoholic steatohepatitis, and on further progression to liver disease [12, 13].

Aspartate aminotransferase (AST) and alanine aminotransferase (ALT) are hepatic enzymes whose elevation indicates hepatocellular injury $[11,14]$. Elevated alkaline phosphatase (ALP) is a marker of cholestatic and hepatobiliary disease $[15,16]$. The diagnostic suspicion of hepatobiliary disease marked by elevated plasma ALP and aminotransferases in HIV patients has been earlier reported [17]. Although reports of elevations in these hepatic enzymes are frequent in HIV-infected patients, direct reports of hepatic injury are limited, due to loopholes in case definition [9]. Several studies suggest possible associations of chronically elevated liver enzyme levels and an increased mortality [18, 19] in HIV-infected and HIV-uninfected patients irrespective of the causal mechanisms.

Managing liver disease is an important component of the care of HIV infected individuals. However, there is limited study that evaluated the burden and causes of liver enzyme abnormality among HIV patients in Nigeria. The aim of this study was to determine the presence of liver enzyme abnormalities among HIV infected patients. 


\section{Materials and Methods}

\subsection{Study Area}

The study recruited HIV/AIDS patients attending Federal Medical Centre (FMC) Makurdi, Nigeria. The hospital is the largest in Benue state and located in Makurdi, the capital city of the state, Northcentral Nigeria. It renders tertiary health care service to a very high patient load. Since FMC is a government hospital rendering relatively cheap services with skilled medical personnel, people of low socio-economic status patronize this hospital. The hospital provides many health care services including HIV testing, counseling and administration of ART.

\subsection{Study Participants}

Institutional ethical clearance and informed patients consent were obtained. A total of 60 participants aged 18 to 60 years comprising of 30 males and 30 females were recruited from patients, attending FMC Makurdi from April to July 2017.

\subsection{Study Design}

Twenty of the recruited HIV patients who have never accessed anti-retroviral drugs were tagged ART-naïve HIV patients. Twenty HIV patients who were accessing HAART with strict adherence to the drug regimen were referred follow-up patients. The control group comprised of $20 \mathrm{HIV}$ seronegative patients attending general health check-up at the hospital. The case-control study compared AST, ALT, ALP and cluster of differentiation (CD4+) cell count among ART-naïve HIV patients $(n=20)$, follow-up patients $(n=20)$ and apparently healthy controls $(n=20)$.

\subsection{Laboratory Methods}

Four milliliter of venous blood samples were separately collected, aseptically into ethylene diamine tetra-acetic acid (EDTA) and plain vacutainer tubes for the respective determination of CD4+ cells and liver enzymes from each participant. The CD4+ cell count was determined by flow cytometry using Partec cyflow machine (Counter 2 model and SL/3). Liver enzymes were analyzed with Hitachi automated chemistry analyzer (902 model). All laboratory analyses adhered to standard operating procedures in FMC laboratory which is nationally accredited.

\subsection{Statistical Methods}

Data were presented as means and standard deviations for continuous variables. Analysis of variance was used for between-group assessments, followed by least significant difference post hoc significant difference test. All statistical analyses were performed using the IBM Armonk, NY, USA, SPSS version 21. A two-sided P<0.05 was considered statistically significant.

\section{Results}

Liver enzymes and CD4+ cell count in the study participants is presented in table 1 . A significant $(\mathrm{P}<0.02)$ change was observed in mean enzyme levels and CD4+ cell count among the groups compared. A detailed result by a post hoc test is presented in table 2. Serum AST, ALP levels of ART-naïve patients was significantly $(\mathrm{P}<0.05)$ higher than that of follow-up and controls. Serum ALT levels of controls were significantly $(\mathrm{P}<0.01)$ lower than that of ART-naïve and follow-up patients. The CD4+ cell count of ART-naïve patients was significantly $(\mathrm{P}=0.000)$ lower than that of follow-up and control groups.

Table-1. Liver enzymes and CD4+ cells in the study groups

\begin{tabular}{l|l|l|l|l|l}
\hline Parameters & $\begin{array}{l}\text { ART-naïve } \\
(\mathbf{n = 2 0})\end{array}$ & $\begin{array}{l}\text { Follow-up } \\
(\mathbf{n = 2 0})\end{array}$ & $\begin{array}{l}\text { Control } \\
(\mathbf{n = 2 0})\end{array}$ & F-value & P-value \\
\hline AST & $40.82 \pm 21.77$ & $27.80 \pm 6.25$ & $23.46 \pm 4.21$ & 9.227 & $0.000^{*}$ \\
\hline ALT & $23.49 \pm 7.41$ & $22.12 \pm 7.48$ & $16.39 \pm 3.73$ & 6.821 & $0.002 *$ \\
\hline ALP & $106.50 \pm 44.94$ & $87.50 \pm 10.09$ & $81.07 \pm 18.14$ & 4.281 & $0.019 *$ \\
\hline CD4+ & $156.80 \pm 152.55$ & $451.20 \pm 229.18$ & $812.20 \pm 281.19$ & 41.750 & $0.000^{*}$ \\
\hline
\end{tabular}

*significant, aspartate aminotransferase (AST), alanine aminotransferase (ALT), alkaline phosphatase (ALP), cluster of differentiation 4 (CD4+) cells

Table-2. Post-hoc test amongst the groups studied

\begin{tabular}{|c|c|c|c|c|c|c|c|c|c|}
\hline & $\begin{array}{l}\text { ART-naïve } \\
(\mathrm{n}=20)\end{array}$ & $\begin{array}{l}\text { Follow-up } \\
(\mathrm{n}=20)\end{array}$ & $\begin{array}{l}P \text { - } \\
\text { value }\end{array}$ & $\begin{array}{l}\text { ART-naïve } \\
(n=20)\end{array}$ & $\begin{array}{l}\text { Control } \\
(n=20)\end{array}$ & $\begin{array}{l}\text { P- } \\
\text { value }\end{array}$ & $\begin{array}{l}\text { Follow-up } \\
(\mathrm{n}=20)\end{array}$ & $\begin{array}{l}\text { Control } \\
(\mathrm{n}=20)\end{array}$ & $\begin{array}{l}\text { P- } \\
\text { value }\end{array}$ \\
\hline$\overline{\mathrm{AST}}$ & $40.82 \pm 21.77$ & $27.80 \pm 6.25$ & $0.003^{*}$ & $40.82 \pm 21.77$ & $23.46 \pm 4.21$ & $0.000^{*}$ & $27.80 \pm 6.25$ & $23.46 \pm 4.21$ & 0.307 \\
\hline ALT & $23.49 \pm 7.41$ & $22.12 \pm 7.48$ & 0.504 & $23.49 \pm 7.41$ & $16.39 \pm 3.73$ & $0.001 *$ & $22.12 \pm 7.48$ & $16.39 \pm 3.73$ & $0.007^{*}$ \\
\hline ALP & $106.50 \pm 44.94$ & $87.50 \pm 10.09$ & $0.040^{*}$ & $106.50 \pm 44.94$ & $81.07 \pm 18.14$ & 0.007 & $87.50 \pm 10.09$ & $81.07 \pm 18.14$ & 0.480 \\
\hline CD4+ & $156.80 \pm 152.55$ & $451.20 \pm 229.18$ & $0.000^{*}$ & $156.80 \pm 152.55$ & $812.20 \pm 281.19$ & $0.000^{*}$ & $451.20 \pm 229.18$ & $812.20 \pm 281.19$ & $0.000^{*}$ \\
\hline
\end{tabular}

*significant, aspartate aminotransferase (AST), alanine aminotransferase (ALT), alkaline phosphatase (ALP), cluster of differentiation 4 (CD4+) cells

\section{Discussion}

The present study observed elevated AST, ALP in ART naïve HIV patients compared to follow-up patients and controls. This observation is in consonance with emerging evidence that HIV infection, even in the absence of ART toxicity and other co-factors may have a direct impact on liver pathogenesis [12,13]. Liver pathogenesis has been attributed to the impact of HIV infection on chronic immune system activation, inflammatory cytokine release and 
oxidative stress [12, 13]. In another study involving ART-naive HIV-infected and HIV-uninfected Rwandan women, the prevalence of liver aminotransferase abnormalities and impaired synthetic function was higher in HIV positive than HIV negative women [20]. Our finding is also consistent with a Nigerian study conducted by Ejilemele et al., who reported common liver enzymes abnormalities in HIV patients [21]. The study of Mata-Marin et al., found an association between HIV viral load and aminotransferases as markers of hepatic damage in ART naïve patients [11].

The present study observed normal AST and ALT levels in follow-up patients; ALT levels were however significantly high compared to controls and no significant change in ALT when compared to ART naïve HIV patients. This finding is similar to the study of Ocama et al., (Uganda) and Osakunor et al., (Ghana) who observed a low frequency of liver enzyme elevation in HIV patients on ART [22, 23]. Osakunor et al., did not observe any significant increase in liver enzymes in ART naïve HIV patients compared with ART HIV patients [22]. Contrary to other studies; a study of prevalence and factors associated with liver test abnormalities among HIV-infected persons in San Diego, California found that $27 \%$ of HIV patients had abnormal liver test results during a 6-month study period after ART initiation [8]. Studies conducted by Owiredu et al., and Shiferaw et al., have reported higher ALT level on HAART experienced HIV patients [24, 25].

The present study observed a significant higher ALP level in ART naïve patients compared to ART patients and controls. This finding is similar with that of Patil et al., who found higher ALP levels in HIV positive patients relative to HIV negative controls [15]. Marked elevations in serum ALP levels have been previously reported in $17 \%$ of HIV patients [26]. In another series, cholestasis was observed in up to 55\% HIV-infected patients [27, 28]. Cholestasis is defined as biliary excretory failure or obstruction of the biliary tree caused by a variety of factors. It is reflected clinically in elevated serum ALP with or without hyperbilirubinemia [16, 29]. Cholestatic liver disease in patients infected with HIV is linked with infiltrating opportunistic infections [30].

The present study observed low CD4+ cell count in ART naïve patients compared to follow-up patients and controls. A relatively high CD4+ cell count was observed in controls compared to follow-up patients. The significant changes in CD4+ cell count observed in follow-up are indicative of responsiveness of HIV patients to ART. Upon HIV infection, it is expected that CD4 lymphocyte count will drop as HIV infection progresses, and ART is expected to enhance the rise of CD4+ numbers. Research Findings have shown that, after ART, the median CD4+ cell counts increase with time [31]. Adherence to therapy may also be a contributing factor to achieving the purpose of therapy in HIV patients [31]. The observation of a decrease in CD4+ cell count along with an increase in AST, ALP in ARTnaïve HIV patients compared to follow-up and control groups could be caused by opportunistic infections as a result of immunosuppression. Shiferaw et al., reported an association between CD4+ cell count $(<200$ cells $/ \mathrm{mm} 3)$ and elevated liver enzyme among highly active ART (HAART) experienced and HAART naive HIV-1 infected patients in a hospital setting in North West, Ethiopia [25]. As immunodeficiency progresses (CD4<200cells/mm3) the liver is involved by systemic opportunistic infections [17].

Associations between opportunistic infections and elevated liver enzymes have been previously reported in HIV patients [32-34]. Despite the no determination of opportunistic infections in this present study, liver enzyme abnormalities might be due to opportunistic infections; viruses, mycobacteria, and fungi which are known to affect the liver and manifested as elevated liver enzymes [7].

Mechanisms by which HIV causes hepatic damage are still unknown. Studies suggest that HIV can alter the permeability of the gastrointestinal tract, leading to increased levels of circulating lipopolysaccharide that may affect liver function parameters [35]. Abnormalities in liver function tests could be produced exclusively by direct inflammation in hepatocytes, caused by the virus. The most important mechanisms could be apoptosis (induced by caspases 2, 7 and 8) and mitochondrial dysfunction with decreasing mitochondrial DNA in several tissues; another injury mechanism is permeability alteration in the mitochondrial membrane by HIV proteins which stimulate an inflammatory response [9, 36, 37].

Conclusion

We found liver enzyme abnormalities in ART naïve HIV infected patients. Therefore, monitoring and management of liver enzyme abnormalities in HIV infected patients are essential. There are prospects of ART impacting on the improvement of liver function in HIV patients.

\section{Reference}

[1] UNAIDS, 2017. "UNAIDS Data. Joint United Nations Programme on HIV/AIDS, Geneva Switzerland."

[2] Morse, C. G. and Kovacs, J. A., 2006. "Metabolic and skeletal complications of HIV infection, The price of success." JAMA, vol. 296, pp. 844-854.

[3] Smith, C., Sabin, C. A., and Lundgren, J. D., 2010. "Factors associated with specific causes of death amongst HIV-positive individuals in the D:A:D Study." AIDS, vol. 24, pp. 1537-1548.

[4] Martın-Carbonero, L., Soriano, V., Valencia, E., Garcia-Samaniego, J., Lopez, M., and Gonzalez-Lahoz, J., 2001. "Increasing impact of chronic viral hepatitis on hospital admissions and mortality among HIVinfected patients." AIDS Research and Human Retroviruses, vol. 17, pp. 1467-1471.

[5] Castellares, C., Barreiro, P., Martin-Carbonero, L., Labarga, P., E., V. M., and Casado, R., 2008. "Liver cirrhosis in HIV-infected patients: prevalence, aetiology and clinical outcome." Journal of Viral Hepatitis, vol. 15 , pp. $165-172$

[6] Richardson, J. and Melester, D., 2003. "Treatment AIDs." Clinical Liver Disease, vol. 7, pp. 475-499.

[7] Butt, A., 2012. "Epidemiology of liver disease in human immunodeficiency virus-nfectedpersons." Available: $\quad$ http://www.springer.com/cda/content/document/cdadownloaddocument/9781441917119c1.pdf?SGWID=0-0-45-1260039-p174243173 
[8] Crum-Cianflone, N., Collins, G., Medina, S., Asher, D., Campin, R., and Bavaro, M., 2010. "Prevalence and factors associated with liver test abnormalities among human immunodeficiency virus-infected persons." Clinical Gastroenterology and Hepatology, vol. 8, pp. 183-191.

[9] Pol, S., Lebray, P., and Vallet-Pichard, A., 2004. "HIV infection and hepatic enzyme abnormalities: Intricacies of the pathogenic mechanisms." Clin. Infect. Dis., vol. 38, pp. S65-72.

[10] Sulkowski, M. S., 2008. "Management of hepatic complications in HIV-infected persons." Journal of Infectious Diseases, vol. 197, pp. S279-S293.

[11] Mata-Marin, J. A., Gaytan-Martinez, J., Grados-Chavarria, B. H., Fuentes-Allen, J. L., Arroyo-Anduiza, C. I., and Alfaro-Mejía, A., 2009. "Correlation between HIV viral load and aminotransferases as liver damage markers in HIV infected naïve patients, A concordance cross-sectional study." Virol. J,, vol. 6, p. 181.

[12] Crum-Cianflone, N., Dilay, A., Collins, G., Asher, D., Campin, R., and Medina, S., 2009. "Non-alcoholic fatty liver disease among HIV-infected persons." J. Acquir. Immune. Defic. Syndr., vol. 50, pp. 464-473.

[13] Ingiliz, P., Valantin, M. A., Duvivier, C., Medja, F., Dominguez, S., and Charlotte, F., 2009. "Liver damage underlying unexplained transaminase elevation in human immunodeficiency virus-1 mono-infected patients on antiretroviral therapy." Hepatology, vol. 49, pp. 436-442.

[14] Clark, J. M., Brancati, F. L., and Diehl, A. M., 2003. "The prevalence and etiology of elevated aminotransferase levels in the United States." Am. J. Gastroenterol, vol. 98, pp. 960-967.

[15] Patil, R., Kamble, P., and Raghuwanshi, U., 2013. "Serum ALP \& GGT levels in HIV positive patients." International Journal of Recent Trends in Science And Technology, vol. 5, pp. 155-157.

[16] Te, H. S., 2004. "Cholestasis in HIV-infected patients." Clin. Liv. Dis., vol. 8, pp. 213 - 228. Available: https://doi.org/10.1016/S1089-3261(03)00129-6

[17] Lizardi-Cervera, J., Soto, R. L. E., Poo, J. L., and Uribe, M., 2005. "Hepatobiliary diseases in patients with human immunodeficiency virus (HIV) treated with non highly active antiretroviral therapy: frequency and clinical manifestations." Ann. Hepatol, vol. 4, pp. 188-191.

[18] Koethe, J. R., Blevins, M., Nyirenda, C., Kabagambe, E. K., Shepherd, B. E., and Wester, C. W., 2011. "Nutrition and inflammation serum biomarkers are associated with 12-week mortality among malnourished adults initiating antiretroviral therapy in Zambia." J. Int. AIDS. Soc., vol. 14, p. 19.

[19] Ruhl, C. E. and Everhart, J. E., 2009. "Elevated serum alanine aminotransferase and gammaglutamyltransferase and mortality in the United States population." Gastroenterology, vol. 136, pp. 477485.

[20] Dusingize, J. C., Hoover, D. R., Shi, Q., Mutimura, E., Rudakemwa, E., and Ndacyayisenga, V., 2015. "Association of abnormal liver function parameters with HIV serostatus and cd4 count in antiretroviralnaive rwandan women." AIDS research and human retroviruses, vol. 31,

[21] Ejilemele, A. A., Nwauche, C. A., and Ejele, O. A., 2007. "The pattern of abnormal liver enzymes in HIV patients presenting al a Nigerian tertiary hospital." Níger. Postgrad. Med. J. , vol. 14, pp. 306-309.

[22] Ocama, P., Castelnuovo, B., Kamya, M. R., Kirk, G. D., Reynolds, S. J., and Kiragga, A., 2010. "Low frequency of liver enzyme elevation in HIV-infected patients attending a large urban treatment centre in Uganda." Int. J. STD. AIDS., vol. 2, pp. 553-557.

[23] Osakunor, D. N., Obirikorang, C., Fianu, V., Asare, I., and Dakorah, M., 2015. "Hepatic enzyme alterations in HIV patients on antiretroviral therapy: A case-control study in a hospital setting in Ghana." PLOS ONE, vol. 10, p. e0134449.

[24] Owiredu, W. K., Quaye, L., and Amidu, N., 2011. "Oxidative stress and Dyslipidaemia among Ghanaian HAART-na"1ve HIV patients and those on HAART." West African Journal of Pharmacy, vol. 22, pp. 5866.

[25] Shiferaw, M. B., Tulu, K. T., Zegeye, A. M., and Wubante, A. A., 2016. "Liver enzymes abnormalities among highly active antiretroviral therapy experienced and haart nalve hiv-1 infected patients at debre tabor hospital, north west ethiopia: A comparative cross-sectional study. Aids research and treatment, article id 1985452, 7." Available: http://dx.doi.org/10.1155/2016/1985452

[26] Payne, T. H., Cohn, D. L., Davidson, A. J., Henry, T. D., Schaefer, J. W., and Gabow, P. A., 1991. "Marked elevations of serum alkaline phosphatase in patients with AIDS." J. Acquir. Immune. Defic. Syndr., vol. 4, pp. 238-243.

[27] Bonacini, M., 1992. "Hepatobiliary complications in patients with human immunodeficiency virus infection." Am. J. Med., vol. 92, pp. 404-411.

[28] Gordon, S. C., Reddy, K. R., Gould, E. E., McFadden, R., O'Brien, C., and De Medina, M., 1986. "The spectrum of liver disease in the acquired immunodeficiency syndrome." J. Hepatol, vol. 2, pp. 475-484.

[29] Poles, M. A., Lew, E. A., and Dieterich, D. T., 1997. "Diagnosis and treatment of hepatic disease in patients with HIV." Gastroenterol Clin. North. Am., vol. 26, pp. 291-321.

[30] Price, J. C. and Thio, C. L., 2010. "Liver disease in the HIV-infected individual." Clin. Gastroenterol Hepatol, vol. 8, pp. 1002-1012.

[31] Federal Ministry of Health Abuja - Nigeria, 2016. "National guidelines for HIV and AIDS treatment and care. Apps.Who.Int/medicinedocs/documents/s23252en/s23252en.Pdf."

[32] Al Anazi, A. R., 2009. "Gastrointestinal opportunistic infections in human immunodeficiency virus disease." Saudi. J. Gastroenterol, vol. 15, pp. 95-99.

[33] Cappell, M. S., 1991. "Hepatobiliary manifestations of the acquired immune deficiency syndrome." Am. J. Gastroenterol, vol. 86, pp. 1-15. 
[34] Terzic, D., Brmbolic, B., Singer, D., Dupanovic, B., Korac, M., and Selemovic, D., 2008. "Liver enlargement associated with opportunistic infections in patients with human immunodeficiency virus infection." J. Gastrointestin Liver. Dis., vol. 17, pp. 401-404.

[35] Crane, M., Iser, D., and Lewin, S. R., 2012. "Human immunodeficiency virus infection and the liver." World. J. Hepatol., vol. 4, pp. 91-98.

[36] Cote, H. C., Brumme, Z. L., Craib, K. J., Alexander, C. S., Wynhoven, B., and Ting, L., 2002. "Changes in mitochondrial DNA as a marker of nucleoside toxicity in HIV-infected patients." N. Engl. J. Med., vol. 346, pp. 811-20.

[37] Guaraldi, G., Squillace, N., Stentarelli, C., Orlando, G., D'Amico, R., and Ligabue, G., 2008. "Nonalcoholic fatty liver disease in HIV infected-patients referred to a metabolic clinic: prevalence, characteristics, and predictors." Clin. Infect. Dis., vol. 47, pp. 250-257. 